\section{Case Reports in Ophthalmology}

Case Rep Ophthalmol 2020;11:574-581

DOI: 10.1159/000510631

Published online: November 2, 2020

(c) 2020 The Author(s)

Published by S. Karger AG, Basel

www.karger.com/cop

This article is licensed under the Creative Commons Attribution-NonCommercial 4.0 International License (CC BY-NC) (http://www.karger.com/Services/OpenAccessLicense). Usage and distribution for commercial purposes requires written permission.

\title{
Successful Treatment of Acute Endophthalmitis after Cat Bite: A Case Report and Review of the Literature
}

\author{
Kamal Kishore ${ }^{a, b}$ Daniel S. McGowan ${ }^{b} \quad$ Robert P. Pode ${ }^{c}$ \\ allinois Retina and Eye Associates, Peoria, IL, USA; ${ }^{b}$ Department of Surgery, University of \\ Illinois College of Medicine, Peoria, IL, USA; 'Finkelstein Eye Associates, Peru, IL, USA
}

\section{Keywords}

Acute endophthalmitis - Cat bite · Alpha hemolytic Streptococcus · Bacillus · Case report

\section{Abstract}

Endophthalmitis after cat bite has poor outcome particularly those associated with scleral injury. A 33-year-old Caucasian female was seen by her ophthalmologist 4 days after cat bite to her right eye with hand motion vision and obvious signs of acute endophthalmitis. She was treated with exploration and repair of scleral puncture wound, anterior chamber and vitreous cultures and intravitreal injections of vancomycin and ceftazidime. Cultures were positive for alpha hemolytic Streptococcus. She underwent a pars plana vitrectomy, cultures and repeat injection of the same antibiotics and intravitreal dexamethasone 2 days later. Cultures grew Bacillus. Endophthalmitis resolved and she regained 20/20 vision after cataract surgery 3 months later. Successful outcome of acute endophthalmitis following a cat bite to the sclera in this case was most likely due to prompt intravitreal antibiotics and early vitrectomy combined with supplemental intravitreal antibiotics and steroid therapy. 


\section{Case Reports in Ophthalmology}

\section{Introduction}

Approximately $34 \%$ of US households have cats as pets, and they are responsible for $10 \%$ of all animal bites, or approximately 400,000 cases per year in the US [1].The most common organisms isolated from the oral cavity of cats include alpha hemolytic Streptococci $(23 \%)$, Staphylococci (18\%), Neisseria (16\%) and Pasteurella (12\%) [2]. The most common types of infections from cat bites are cellulitis (42\%), purulent wounds without abscess formation (39\%), and abscesses (19\%) [3]. Infections resulting from cat bites tend to be polymicrobial in nature with a variety of aerobic and anaerobic organisms having been isolated. Pasteurella multocida is the most common organism isolated from cat bite wounds (75\%) followed by Streptococci (46\%), Staphylococci (35\%) and Bacillus (11\%) [4].

There are only eight reported cases of endophthalmitis after a cat bite or scratch in the English literature [5-12]. The most common organism was Pasteurella (6/8) and most eyes had poor outcomes. The purpose of this communication is to report a case of acute endophthalmitis after scleral penetration from a cat bite that was successfully treated with scleral wound repair and intravitreal antibiotics followed 2 days later by vitrectomy, intravitreal antibiotics and steroid injection.

\section{Case Report}

A 33-year-old Caucasian female presented to her ophthalmologist with the complaints of progressively worsening eye pain, redness and loss of vision in the right eye of 1-day duration. She gave a history of being bitten on the right eye by her domestic cat 4 days earlier. She was prescribed a course of oral amoxicillin-clavulanate potassium (Augmentin ${ }^{\circledR}$ ) after being seen in the emergency department on the day of the injury. Rabies prophylaxis was not indicated according to the Centers for Disease Control and Prevention (CDC) guidelines [13]. Her past ocular history was significant for mild myopia. Her medical history was significant for an anxiety disorder which was being treated with oral paroxetine (Paxil ${ }^{\circledR}$ ).

Her best-corrected visual acuity at presentation was hand motion in the right eye and 20/20 in the left. External examination showed healing abrasions on the nasal aspect of the left lower lid. Slit-lamp examination of the right eye showed 2+ conjunctival congestion, a healing conjunctival laceration nasally, clear cornea, $1 \mathrm{~mm}$ hypopyon and $3+$ cells and flare in the anterior chamber, irregular pupil due to posterior synechiae, and a clear lens. The left eye was normal. The intraocular pressures were $10 \mathrm{~mm} \mathrm{Hg}$ OD and $15 \mathrm{~mm} \mathrm{Hg}$ OS by applanation tonometry. Dilated fundus examination of the right showed dense vitritis without any view of the nerve or retinal details. The left eye was normal.

The patient was taken to the operating room for exploration of the globe which revealed a puncture wound $3 \mathrm{~mm}$ behind the limbus in the inferonasal quadrant (Zone 2 injury) [14]. A vitreous strand presenting through the wound was excised with scissors, and the puncture wound was repaired with two interrupted 8-0 nylon sutures. Anterior chamber and vitreous tap were performed, and the specimens were sent for culture and sensitivity. Intravitreal injections of vancomycin $1 \mathrm{mg} / 0.1 \mathrm{~mL}$ and ceftazidime $2.25 \mathrm{mg} / 0.1 \mathrm{~mL}$ were administered with separate 30 -g needles through the pars plana. She also received intravenous vancomycin $1 \mathrm{gm}$ every $12 \mathrm{~h}$ and intravenous gentamicin $100 \mathrm{mg}$ loading dose followed by $50 \mathrm{mg}$ every $8 \mathrm{~h}$ for 


\section{Case Reports in Ophthalmology}

Case Rep Ophthalmol 2020;11:574-581

DOI: $10.1159 / 000510631$

(c) 2020 The Author(s). Published by S. Karger AG, Basel www.karger.com/cop

Kishore et al.: Cat Bite Endophthalmitis

$24 \mathrm{~h}$. In addition, she was started on $1 \%$ prednisolone acetate eye drops every hour, $0.3 \%$ moxifloxacin eye drops every $2 \mathrm{~h}$, and $1 \%$ atropine eye drops every $12 \mathrm{~h}$ in the right eye. The culture from the anterior chamber was sterile but the vitreous tap grew alpha hemolytic Streptococcus.

The patient was examined by a retina specialist $24 \mathrm{~h}$ after the initial repair. The corrected visual acuity in the right eye was hand motion and 20/20 in the left. The right eye showed a subconjunctival hemorrhage and interrupted polyglactin 910 (Vicryl ${ }^{\circledR}$ ) sutures over the nasal bulbar conjunctiva. The cornea was clear (Fig. 1). The anterior chamber showed mild cells and flare. The pupil was pharmacologically dilated with a few posterior synechiae. The lens appeared clear. Dense exudates were seen in the vitreous cavity (Fig. 2). B scan ultrasonography showed the retina to be attached. The intraocular pressures were 15- and 18-mm Hg in OD and $\mathrm{OS}$, respectively, by Goldmann applanation tonometry. The left eye was normal.

A 25-gauge vitrectomy was performed on the following day, approximately $48 \mathrm{~h}$ after initial repair. Approximately $1.5 \mathrm{~mL}$ of undiluted vitreous sample was obtained by activating the cutter in the midvitreous cavity under wide-field visualization and manual aspiration by an assistant with a 3-mL syringe under air infusion. The specimen was sent for gram stain, as well as aerobic, anaerobic, bacterial and fungal cultures. The infusion was switched to fluid and a thorough vitrectomy was performed including removal of as much peripheral vitreous as possible using a 500-mL BSS Plus ${ }^{\circledR}$ (Alcon, Fort Worth, TX, USA) bottle to which 2 mg gentamicin ( $4 \mu \mathrm{g} / \mathrm{mL}$ concentration), $32 \mathrm{mg}$ dexamethasone ( $64 \mu \mathrm{g} / \mathrm{mL}$ concentration), and $1 \mathrm{mg}$ epinephrine had been added. The lens was clear and was not removed.

After completion of vitrectomy, vancomycin $(1 \mathrm{mg} / 0.1 \mathrm{~mL})$, ceftazidime $(2.25 \mathrm{mg} / 0.1$ $\mathrm{mL}$ ) and dexamethasone ( $400 \mu \mathrm{g} / 0.1 \mathrm{~mL})$ were injected into the vitreous cavity via separate syringes. Subconjunctival cefazolin and dexamethasone injections were also given.

Topical prednisolone acetate, moxifloxacin and atropine drops were resumed after vitrectomy and slowly tapered off over the next 3 weeks. Aerobic cultures from the vitreous demonstrated heavy growth of Bacillus species. Anaerobic and fungal cultures were negative.

Her endophthalmitis resolved but she developed a dense posterior subcapsular cataract which was removed by an uncomplicated phacoemulsification and in-the-bag placement of a posterior chamber intraocular lens (PCIOL) 3 months after injury. Postoperatively, her vision improved to $20 / 20$ and has remained at that level for more than 3 years of follow-up.

\section{Discussion}

Eight reported cases of endophthalmitis following cat bite or scratch are summarized in Table 1 . The mean age was 15 years (range 1-51 years, M/F 4/4). OD was affected in 3 and OS in 4 (N/A in 1). The location of injury was cornea in 3 and sclera in 5 (3 in Zone 3, N/A in 2). Endophthalmitis was diagnosed after a mean 2.4 (range 1-4) days after injury. The presenting vision was generally poor (light perception in 2, 20/250 in 1,6/60 in 1, and N/A in 4). Causative organisms were Pasteurella 6 (P. multocida 5, P. septica 1), Pseudomonas aeruginosa 1, Capnocytophaga 1, and Neisseria 1. Pars plana vitrectomy (PPV) was performed in 5 eyes. Intravitreal antibiotic injections were administered in 3 eyes; 2 at the same time as PPV. One eye undergoing PPV received $4 \mu \mathrm{g} / \mathrm{mL}$ tobramycin in the infusion fluid but no other intravitreal antibiotic therapy [7]. Retinal detachment developed in three eyes [7, 8, 11], and was 


\section{Case Reports in Ophthalmology}

Case Rep Ophthalmol 2020;11:574-581

DOI: $10.1159 / 000510631$

(C) 2020 The Author(s). Published by S. Karger AG, Basel www.karger.com/cop

Kishore et al.: Cat Bite Endophthalmitis

successfully reattached in two eyes after multiple surgeries [7, 8]. One eye was eviscerated [5]. Final visual acuity was not available for one eye. In the remaining six eyes, the final vision was $\leq 20 / 200$ in 4 . One eye had two vitrectomies to control endophthalmitis which resolved without retinal detachment. That eye was treated with intravitreal gentamicin and cephazolin and had final vision of light perception [9]. It is not known whether vision was lost from gentamicin toxicity or some other reason [15]. All three eyes that developed retinal detachment had $\leq 20 / 200$ vision. One eye each had 20/30 and 20/40 final vision $[6,10]$. Both of them had corneal lacerations. One of them received neither vitrectomy nor intravitreal therapy at the time of repair of corneal laceration 2 days after injury [6], and the other underwent PPV without intravitreal antibiotic administration at the same time as repair of corneal laceration on the day of the injury [10]. It is therefore plausible that these two eyes had sterile inflammation and not true endophthalmitis.

Alpha hemolytic or viridans group Streptococci are a large and heterogeneous group of organisms. First classified into 3 species in 1912, there are currently at least 30 species of VGS subclassified into six major groups [16]. These are commensals in the oral pharynx of humans and animals, and are known to cause a variety of infections, most notably infective endocarditis. In ophthalmology, endophthalmitis caused by alpha hemolytic Streptococci has gained a lot of attention in recent years as being a relatively common cause of post intravitreal injection endophthalmitis [17]. Most cases of endophthalmitis from alpha hemolytic Streptococci have poor outcomes due to their high virulence and production of endotoxins [18].

Bacillus endophthalmitis is a major bacterial pathogen causing traumatic endophthalmitis, particularly in rural settings [19]. It is notorious for causing rapidly progressing eye infection with severe pain, corneal ring infiltrates, and extraocular spread leading to the loss of the eye due to its rapid multiplication rate and production of exotoxins. Many Bacillus species produce beta lactamase and are intrinsically resistant to penicillins and cephalosporins.

Lens extraction at the time of vitrectomy for endophthalmitis has been recommended [20], and is our standard practice in most cases with cloudy anterior segment due to corneal edema, fibrin and/or hypopyon. Our preference is to remove the lens by phacoemulsification followed by removal of capsular bag with forceps. However, we were able to perform a thorough vitrectomy using a wide-field viewing system, and lens extraction was not needed during PPV in this case. It is advantageous to retain the lens if possible so that an intraocular lens can be placed in the bag during subsequent phacoemulsification. Although speculative, addition of intravitreal antibiotics and steroids in the infusion fluid, and intravitreal dexamethasone injection has the potential to favorably influence the outcome [21].

The potential role of amoxicillin-potassium clavulanic acid in improving the outcome in this patient remains speculative. Clavulanic acid is an inhibitor of beta lactamase and this combination is effective against many beta lactamase-producing organisms. Amoxicillin penetrates well into the cerebrospinal fluid, particularly in patients with inflamed meninges and can be used to treat bacterial meningitis [22]. However, it had poor vitreous penetration in a rabbit model [23]. While it might penetrate better into an inflamed eye with severe breakdown of blood retinal barrier, it is unlikely that oral amoxicillin by itself would be able to sterilize the vitreous cavity in the setting of endophthalmitis.

To conclude, we present a patient who developed acute endophthalmitis following a cat bite to the sclera (Zone 2 injury) caused by alpha hemolytic Streptococci and Bacillus, and had an excellent visual outcome after intravitreal antibiotic injections at the time of initial surgical 


\section{Case Reports in Ophthalmology}

repair followed by a thorough vitrectomy with supplemental intravitreal antibiotics and steroids after 2 days. An excellent outcome in this patient with multiple risk factors for poor outcome according to Ocular Trauma Score (initial vision of hand motion, Zone 2 injury and endophthalmitis) [24], vitreous prolapse [25], and endophthalmitis caused by two virulent organisms is very encouraging. Consideration should be given to obtaining vitreous culture and administration of intravitreal antibiotics at the time of wound exploration and globe repair in potentially infected injuries including animal and human bites.

\section{Statement of Ethics}

All procedures performed were in accordance with the ethical standards of the institutional and/or national research committee and with the 1964 Helsinki Declaration and its later amendments or comparable ethical standards. This is a case report and does not require ethics committee approval. Written informed consent for publication was obtained from all patients.

\section{Conflict of Interest Statement}

The authors have no conflicts of interest to declare.

\section{Funding Sources}

No funding was received.

\section{Author Contributions}

K.K. contributed to the conception of the project, drafting of the manuscript and analysis. D.M. contributed to the acquisition of data and revising of the manuscript. R.P. contributed to the acquisition of data. All authors read and approved the final manuscript.

\section{References}

1 Goldstein EJ, Abrahamian FM. Diseases Transmitted by Cats. Microbiol Spectr. 2015 Oct;3(5): https://doi.org/10.1128/microbiolspec.IOL5-0013-2015.

2 Whyte A, Gracia A, Bonastre C, Tejedor MT, Whyte J, Monteagudo LV, et al. Oral Disease and Microbiota in Free-Roaming Cats. Top Companion Anim Med. 2017 Sep;32(3):91-5.

3 Talan DA, Citron DM, Abrahamian FM, Moran GJ, Goldstein EJ; Emergency Medicine Animal Bite Infection Study Group. Bacteriologic analysis of infected dog and cat bites. N Engl J Med. 1999 Jan;340(2):85-92.

4 Abrahamian FM, Goldstein EJ. Microbiology of animal bite wound infections. Clin Microbiol Rev. 2011 Apr;24(2):231-46.

5 Galloway NR, Robinson GE. Panophthalmitis due to Pasteurella septica. Br J Ophthalmol. 1973 Mar;57(3):153-5. 


\section{Case Reports in Ophthalmology}

\begin{tabular}{l|l}
\hline Case Rep Ophthalmol 2020;11:574-581 \\
\hline DOI: 10.1159/000510631 & $\begin{array}{l}\text { (c) 2020 The Author(s). Published by S. Karger AG, Basel } \\
\text { www.karger.com/cop }\end{array}$ \\
\hline
\end{tabular}

Kishore et al.: Cat Bite Endophthalmitis

6 Puliafito CA, Baker AS, Haaf J, Foster CS. Infectious endophthalmitis. Review of 36 cases. Ophthalmology. 1982 Aug;89(8):921-9.

7 Yokoyama T, Hara S, Funakubo H, Sato N. Pasteurella multocida endophthalmitis after a cat bite. Ophthalmic Surg. 1987 Jul;18(7):520-2.

8 Doi M, Ikeda T, Yasuhara T, Koizumi K, Nakamura T. A case of bacterial endophthalmitis following perforating injury caused by a cat claw. Ophthalmic Surg Lasers. 1999 Apr;30(4):315-6.

9 Vartian CV, Septimus EJ. Endophthalmitis due to Pasteurella multocida and CDC EF-4. J Infect Dis. 1989 Oct;160(4):733.

10 Weber DJ, Wolfson JS, Swartz MN, Hooper DC. Pasteurella multocida infections. Report of 34 cases and review of the literature. Medicine (Baltimore). 1984 May;63(3):133-54.

11 Zimmer-Galler IE, Pach JM. Capnocytophaga canimorsus endophthalmitis. Retina. 1996;16(2):163-4.

12 Iwasaki M, Hikichi T, Muramatsu O, et al. A Case of Endophthalmitis Resulting from a Cat Bite. Nippon Ganka Kiyo. 2004;55:823-5.

13 CDC. https://www.cdc.gov/rabies/exposure/animals/domestic.html 2017; 2020.

14 Pieramici DJ, Sternberg P Jr, Aaberg TM Sr, Bridges WZ Jr, Capone A Jr, Cardillo JA, et al.; The Ocular Trauma Classification Group. A system for classifying mechanical injuries of the eye (globe). Am J Ophthalmol. 1997 Jun;123(6):820-31.

15 Campochiaro PA, Conway BP. Aminoglycoside toxicity - a survey of retinal specialists. Implications for ocular use. Arch Ophthalmol. 1991 Jul;109(7):946-50.

16 Menon T. Understanding the viridians group streptococci: are we there yet? Indian J Med Microbiol. 2016 Oct-Dec;34(4):421-6.

17 Chen E, Lin MY, Cox J, Brown DM. Endophthalmitis after intravitreal injection: the importance of viridans streptococci. Retina. 2011 Sep;31(8):1525-33.

18 Matthews JL, Dubovy SR, Goldberg RA, Flynn HW Jr. Histopathology of streptococcus mitis/oralis endophthalmitis after intravitreal injection with bevacizumab: a report of 7 patients. Ophthalmology. 2014 Mar;121(3):702-8.

19 Bhagat N, Nagori S, Zarbin M. Post-traumatic Infectious Endophthalmitis. Surv Ophthalmol. 2011 May-Jun;56(3):214-51.

20 Diamond JG. Intraocular management of endophthalmitis. A systematic approach. Arch Ophthalmol. 1981 Jan;99(1):96-9.

21 Graham RO, Peyman GA. Intravitreal injection of dexamethasone. Treatment of experimentally induced endophthalmitis. Arch Ophthalmol. 1974 Aug;92(2):149-54.

22 Bakken JS, Bruun JN, Gaustad P, Tasker TC. Penetration of amoxicillin and potassium clavulanate into the cerebrospinal fluid of patients with inflamed meninges. Antimicrob Agents Chemother. 1986 Sep;30(3): 481-4.

23 Brockhaus L, Goldblum D, Eggenschwiler L, Zimmerli S, Marzolini C. Revisiting systemic treatment of bacterial endophthalmitis: a review of intravitreal penetration of systemic antibiotics. Clin Microbiol Infect. 2019 Nov;25(11):1364-9.

24 Kuhn F, Maisiak R, Mann L, Mester V, Morris R, Witherspoon CD. The Ocular Trauma Score (OTS) [vi.]. Ophthalmol Clin North Am. 2002 Jun;15(2):163-5.

25 Yalcin Tök O, Tok L, Eraslan E, Ozkaya D, Ornek F, Bardak Y. Prognostic factors influencing final visual acuity in open globe injuries. J Trauma. 2011 Dec;71(6):1794-800. 
Case Reports in Ophthalmology

Case Rep Ophthalmol 2020;11:574-581

(C) 2020 The Author(s). Published by S. Karger AG, Basel www.karger.com/cop

Kishore et al.: Cat Bite Endophthalmitis

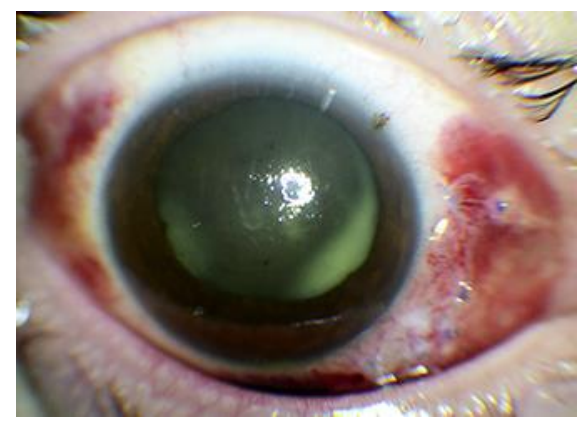

Fig. 1. Anterior segment photograph of the right eye 1 day after repair of scleral laceration and intravitreal antibiotic injection. Note conjunctival sutures on the medial bulbar conjunctiva and exudates in the vitreous cavity.

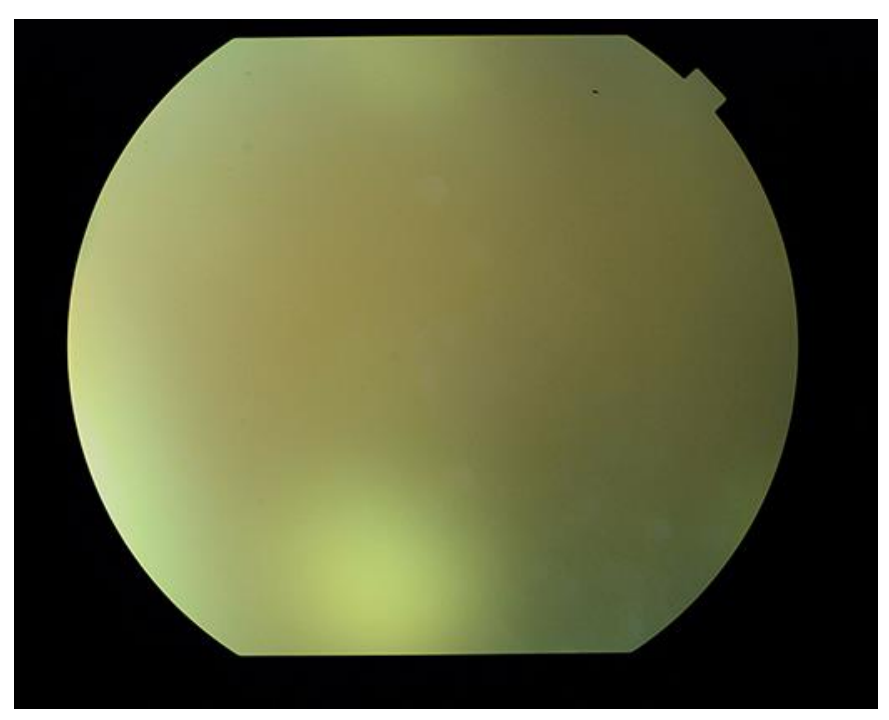

Fig. 2. Fundus photograph of the right eye 1 day after repair of scleral laceration showing dense vitritis without any view of the nerve or blood vessels. 


\section{Case Reports in Ophthalmology}

\begin{tabular}{l|l}
\hline Case Rep Ophthalmol 2020;11:574-581 \\
\hline DOI: 10.1159/000510631 & $\begin{array}{l}\text { ( ) 2020 The Author(s). Published by S. Karger AG, Basel } \\
\text { www.karger.com/cop }\end{array}$ \\
\hline
\end{tabular}

Kishore et al.: Cat Bite Endophthalmitis

Table 1. Acute endophthalmitis after cat bite

\begin{tabular}{|c|c|c|c|c|c|c|c|c|}
\hline Case & Age/sex & Eye & $\begin{array}{l}\text { Nature (scratch vs. bite); } \\
\text { Location; Zone }\end{array}$ & Organism & $\begin{array}{l}\text { Pars plana } \\
\text { vitrectomy }\end{array}$ & $\begin{array}{l}\text { Intravitreal an- } \\
\text { tibiotics }\end{array}$ & $\begin{array}{l}\text { Presenting vi- } \\
\text { sion }\end{array}$ & Final vision \\
\hline $\begin{array}{l}\text { Galloway } \\
{[5], 1973}\end{array}$ & $11 \mathrm{~F}$ & OD & $\begin{array}{l}\text { Scratch; IT quadrant; } \\
\text { Zone III }\end{array}$ & Pasteurella septica & - & - & $6 / 60$ & Evisceration \\
\hline $\begin{array}{l}\text { Puliafito } \\
{[6], 1982}\end{array}$ & $12 \mathrm{M}$ & $\mathrm{N} / \mathrm{A}$ & $\begin{array}{l}\text { N/A; corneal laceration; } \\
\text { Zone I }\end{array}$ & Pasteurella multocida & - & - & LP & $20 / 40$ \\
\hline $\begin{array}{l}\text { Yokoyama } \\
\text { [7], } 1987\end{array}$ & $51 \mathrm{M}$ & os & $\begin{array}{l}\text { Bite; insertion of MR; } \\
\text { Zone III }\end{array}$ & Pasteurella multocida & + & - & LP & $20 / 400(\mathrm{RD})$ \\
\hline $\begin{array}{l}\text { Doi } \\
{[8], 1999}\end{array}$ & $23 \mathrm{~W}$ & OS & $\begin{array}{l}\text { Scratch; IT quadrant; } \\
\text { Zone III }\end{array}$ & Pseudomonas aeruginosa & + & - & $20 / 250$ & $20 / 200(\mathrm{RD})$ \\
\hline $\begin{array}{l}\text { Vartian } \\
{[9], 1989}\end{array}$ & $8 \mathrm{~F}$ & OD & Scratch; Sclera; N/A & $\begin{array}{l}\text { Pasteurella multocida, Neisseria } \\
\text { animaloris, Neisseria zoodegmatis }\end{array}$ & + & + & $\mathrm{N} / \mathrm{A}$ & LP \\
\hline $\begin{array}{l}\text { Weber } \\
{[10], 1984}\end{array}$ & $10 \mathrm{M}$ & OS & Scratch; Cornea; Zone I & Pasteurella multocida & + & - & $\mathrm{N} / \mathrm{A}$ & $20 / 30$ \\
\hline $\begin{array}{l}\text { Zimmer-Galler } \\
{[11], 1996}\end{array}$ & $8 \mathrm{~F}$ & OS & Bite; Cornea; Zone I & Capnocytophaga canimorsus & + & + & $\mathrm{N} / \mathrm{A}$ & $\begin{array}{l}\text { ?LP (persistent } \\
\text { retinal detach- } \\
\text { ments) }\end{array}$ \\
\hline $\begin{array}{l}\text { Iwasaki } \\
{[12], 2004}\end{array}$ & $1 \mathrm{M}$ & OD & Bite; Sclera; N/A & Pasteurella multocida & - & + & $\mathrm{N} / \mathrm{A}$ & $\mathrm{N} / \mathrm{A}$ \\
\hline
\end{tabular}

IT, inferotemporal; N/A, not available; MR, medial rectus; LP, light perception; RD, retinal detachment. 